\title{
Perspectives of vaccination in Chagas disease revisited
}

\author{
Erney Plessmann Camargo \\ Departamento de Parasitologia, Instituto de Ciências Biomédicas, Universidade de São Paulo, São Paulo, SP, Brasil
}

\begin{abstract}
The perspectives for a Chagas Disease vaccine 30 years ago and today are compared. Antigens and adjuvants have improved, but logistic problems remain the same. Sterilizing vaccines have not been produced and animal models for chronic Chagas have not been developed. Vector control has been successful and Chagas incidence has come to a halt. We do not have a population candidate to vaccination now in Brazil. And if we had, we would not know how to evaluate the success of vaccination in a short time period. A vaccine may not seem important at the moment. However, scientific reasons and incertitudes about the future recommend that a search for a vaccine be continued.
\end{abstract}

Key words: vaccines - animal models - vector control - epidemiological targets - recombinant vaccines

In 1982, Carlos Chagas Filho, then President of the Academy of Sciences of the Vatican, invited Zigman Brener and myself to present, at a meeting celebrating the historical rehabilitation by the Church of Galileo Galilei, a paper about the "Perspectives of vaccination in Chagas disease" (Brener \& Camargo 1982). At one session of this memorable meeting, physicists and astronomers gathered to discuss the Big Bang and, at another, Black Holes. At our session, researchers were asked to present their views on vaccines against parasitic diseases. After the seminal work of Ruth Nussenzweig on the protective potentialities of the circumsporozoite protein of plasmodia, we were quite confident that antiparasitic vaccines would soon be produced. These were days of great hope and optimism, and optimistic we were, my late friend Brener and I.

However, to avoid uncritical optimism, before writing our paper we decided to ask ourselves a few questions and to answer them impartially. I jotted down and kept our preliminary reflections. The paper presented at the Vatican session did not follow the order of the script. We were not bound to that script. We were simply asking and answering the questions that we candidly formulated to ourselves as a brainstorming exercise, not as a paper draft. Now, with three decades gone by, I think that it is worth comparing the "perspectives" as we saw them in 1982 and as I see them now. The questions that we formulated to ourselves were:

\section{Question 1 - Are we going to have a vaccine against Chagas disease in 20 years' time?}

The answer was no. Not then, not now. We submitted at the meeting that the logistics involved in finding protective antigens and to proceed from them to produce and test a Chagas vaccine in field conditions (see Ques-

Corresponding author: erney@cnpq.br

Received 1 April 2009

Accepted 16 June 2009 tion 3) would require more than 20 years, even if we already had a "miracle antigen" at hand. Unfortunately, to complicate the matter of a Chagas vaccine, we were disappointed by the fact that a much acclaimed and supposedly protective surface protein of Trypanosoma cruzi had just turned out to be an artefact, not the acclaimed "miracle antigen" (Camargo et al. 1982). Three decades later, no such "miracle antigen" of T. cruzi has been proposed and no way has been found to shorten the time necessary to test a vaccine in humans. We are where we were 30 years ago.

Question 2 - If the vaccine is not coming soon, what could we do in the meantime to fight Chagas disease?

We summarily dismissed clinical treatment as a form of controlling Chagas. We also did not think that transmission through blood transfusion was an unsolvable problem and anticipated that legislation and technical improvements would bring transfusive Chagas to a halt. This is happening (Moncayo 2003). As for vertical transmission between mother and newborn, we could not foresee a solution. I still cannot. In summary, for the overall control of Chagas transmission, we undoubtedly favoured the control of its main vector in Brazil, the domiciliated Triatoma infestans. We were enthusiastic about the perspectives of insecticide-based vector control after the results of a large-scale program pioneered by the state of São Paulo in the 1960s. In the 1970s, the scientific community battled for the implementation of a similar program on a national scale. At the Caxambu meetings, Brazil, A Prata, JR Coura, JC Pinto Dias and $\mathrm{Z}$ Brener, to mention a few, insisted on the need to control T. infestans as the best way available to control Chagas disease. Carlos Chagas Filho and other scientists interceded with the government. Documents and petitions circulated between scientists and government. I remember having given an interview to a Brazilian magazine of wide circulation saying that, with the money that the government used to buy one fighter jet, we could control Chagas disease. Well, the interview did not please the military but, as a sign of the changing times, they did not harass me as I expected. In fact, to be fair, the most lucid among them were already committing themselves to 
launch such a Chagas Control Program. In 1982, while we were writing our paper, the Brazilian program for the control of $T$. infestans was still in its infancy, but its initial successes were quite encouraging. We stressed this point in the paper and time proved that we were right. The current results are unquestionable: T. infestans has been eliminated or placed under control in Brazil (Dias 1987, Silveira \& Vinhaes 1999) and in the countries that adhered to the Southern Cone Initiative, except in Bolivia and in a few other South American foci (Schofield et al. 2006). Human transmission of $T$. cruzi by $T$. infestans in Brazil has been curtailed after 30 years since the launching of the program (Massad 2008). However, in 1982 we were afraid that the program could suffer interruptions, opening the way to a dreaded re-colonisation of domiciles by T. infestans (Dias \& Schofield 1999). This did not happen. We were afraid that colonisation by sylvatic triatomines could follow as domiciles were vacated by T. infestans. This did not happen at a significant scale either, and wherever it began to happen it was rapidly circumvented. There was the potential danger that populations of sylvatic T. infestans living in the Bolivian valleys could invade human dwellings, jeopardising control programs in South America (Noireau et al. 2005). As of today, there are no signs of such a phenomenon taking place (Cortez et al. 2007). As to the danger of the development of significant triatomine resistance to BHC, the chemical industry was quick to provide alternative insecticides, such as synthetic pyrethroids with residual effects. After three decades, it became clear that insecticide spraying, housing improvement and strict sanitary surveillance were indeed the best ways to curb T. cruzi domestic transmission, which had historically been the principal source of cases of Chagas disease in Brazil (Dias et al. 2002).

\section{Question 3 - In this scenario, would a vaccine be necessary?}

Yes, for at least three reasons. First, vaccines are the gold standard of prophylaxis for infectious diseases; they should be available for every infectious disease including Chagas disease, irrespective of any other reason. In addition, like other scientists, Brener and I fully appreciated the tremendous scientific challenge posed by a vaccine against Chagas disease and were very well aware of the considerable collateral amount of knowledge that could be gained from this saga regardless of its outcome. Moreover, in 1982 we did not know the results of the vector control program so we considered a vaccine necessary and essential if such a program failed in the immediate, as well as in the remote future. These reasons still prevail.

However, there is a problem today that we did not completely formulate in 1982, although I raised the issue on later occasions (Camargo 1984, 2000).The problem is: to whom would a Chagas vaccine be destined? Which population would be the target for a Chagas vaccine?

If we had had a vaccine on hand in 1982 we would have known exactly which population to vaccinate. In the 1980s, in Brazil alone, there were 25 million people at risk of infection. There were five million chagasic people and 120,000 new cases a year. Seropositivity for
T. cruzi was $4.4 \%$ for the general population and $5 \%$ for children in the 0-4 years age group. Chagas disease in Brazil was present in an area of more than three million $\mathrm{km}^{2}$, including more than 2,400 municipalities. Today, except for the punctual explosions of oral infection cases (see item 5), there are no reports of new acute cases of $T$. cruzi infection. Seropositivity in children has dropped to $0.12 \%$. The number of $T$. infestans captured in domiciles all over Brazil dropped by $99.3 \%$ and, from the 2,400 municipalities formerly infested, no more than 100 or so remain as unimportant foci. There is no defined population at risk of infection (Dias 1987, Silveira \& Vinhaes 1999, Massad 2008).

Thus, there is no population candidate for a vaccine in Brazil at the moment. However, overall in the Americas, there are an estimated 16 million people still infected with T. cruzi and 50-80 million at risk. I cannot predict what is going to happen in the areas at risk, but programs similar to the Southern Cone Initiative are being carried out in Central America and in the Northern cone of South America. Bolivia as well is committed to a triatomine control program. Based on past experience in Brazil, we can foresee the success of these initiatives but, just in case, it would do no harm to have a vaccine.

\section{Question 4 - What should be the requisites of a vac- cine against Chagas disease?}

The 1982 paper was not intended to deal with vector control, but with a vaccine for Chagas disease. Therefore, we proceeded to analyse the requisites that a vaccine should have. Our conclusions have changed little since.

Primum non nocere - Thirty years ago there were serious concerns about antigen-induced autoimmunity and immunosuppression in Chagas disease. Accordingly, we expressed our fears about the potential inconveniencies of antigen-derived vaccines. Presently, although some controversy remains (Leon \& Engman 2001, Kierszenbaum 2003, Tarleton 2003, Hyland \& Engam 2006), it seems that parasite presentation of antigens, that is, parasite persistence, is necessary to induce a focal inflammatory response (Tarleton 2001). The matter is still unsettled, but scientists nowadays are less scared by the spectre of autoimmunity. Thus, my original strong concerns about antigen-induced disease have subsided somewhat, although the "allergic" myocarditis reported by Muniz (Muniz \& Pena Azevedo 1947) after the inoculation of Rhesus monkeys with merthiolate-killed $T$. cruzi still causes me some unrest. This is because large parts of the arguments in favour of and against autoimmunity have centred on experiments in mice. Primates have never been the object of experimental studies.

Sterile immunity - As we said in 1982: "A vaccine which merely attenuates the acute phase of the infection - a procedure possibly acceptable for other infectious diseases - would be of questionable value in Chagas disease.". This was because there was no evidence that the mildness or severity of the acute phase was directly related to the onset and severity or mildness of chronic disease. Clinical records were full of reports on the lack of correlation between both phases (Brener \& Andrade 
1979). Mouse experimental models are inadequate to test this correlation, whereas rabbit, dog and monkey models have not properly coped with the problem. We were afraid that a few infective forms escaping a nonsterilising vaccine could become responsible for a full course of chronic symptoms. For this reason, until the contrary was proved, we considered the sterilising requisite as absolutely mandatory. However, as mandatory as this precept seems to be, to date, the success of vaccination attempts remains measured by the mortality rates of mice in the acute phase of a challenging post-vaccinal infection. Most authors ignore or give little significance to residual patent or sub-patent parasitaemias that may lead to chronic infections. It has actually been shown in humans that parasite persistence in tissue foci is necessary for chronic inflammation and disease (Vago et al. 1996, Anez et al. 1999, Tarleton \& Zhang 1999, Zhang \& Tarleton 1999). Unfortunately, chronic evolution has not been properly evaluated in experimental models mainly because the most common experimental model, the mouse, is inadequate for that purpose.

Effectiveness against all T. cruzi strains - In the paper to the Academy of Sciences of the Vatican we stressed the fact that there were diverse strains of $T$. cruzi and that a vaccine should be effective against them all. However, we did not know at the time the full extent of T. cruzi genetic variability. Ever since, isoenzyme phenotyping and spliced leader gene and ribosomal genotyping revealed a considerable and ever-increasing number of lineages and hybrids (Miles et al. 1978, 2003, Souto et al. 1996, Brisse et al. 2000, Fernandes et al. 2001, Marcili et al. 2009, unpublished observations). The antigenic makeup of these strains is unknown, whereas their immunogenic and pathogenic importance remains to be assessed. Is there a universally protective antigen? Until we know that, a question will remain unaddressed: would a vaccine produced against one strain be effective against all T. cruzi existing strains?

\section{Question 5 - How to evaluate the effectiveness of a Chagas disease vaccine?}

The experimental model - In 1982, we stressed that the mouse model obviously was not an adequate experimental model for Chagas disease. Three decades later, we still lack a widely adopted and satisfactory experimental model for Chagas disease. The mouse is a handy and useful experimental model, but in many systems it is used only for "first approximations" to be followed by tests in more adequate models. This is the case, for instance, of drug screening for effects and toxicity; tropism, infectivity and virulence of infectious agents; antigens, antigen adjuvants and deliverers, and preliminary antibody and cell immune responses. Unfortunately, for Chagas disease, the mouse remained the sole model throughout the years. In Chagas, mice fail to mimic chronic disease as they fail to recognise $T$. cruzi antigens that are important in the human immune response (Galili 1993, Galili \& Andrews 1995). As we said before, and I submit here again, the dog is probably the best lab model for Chagas disease. In nature, dogs develop a human-like Chagas disease, both acute and chronic, and are found naturally infected in the most diverse biomes colonised by man. For these reasons, they are excellent epidemiological sentinels for T. cruzi vectorial transmission (Umezava et al. 2009, unpublished observations). The dog model has only recently been more deeply explored (Valadares et al. 2008, Guedes et al. 2008) and it has been shown that dogs respond to T. cruzi infection with the full cohort of factors and kinins that accompany the human infection (Guedes et al. 2009). I believe that dogs would be the model of choice for testing prospective vaccines, although I agree that it may be an inconvenient model for first approximations because of handling and nursing needs and the emotional objections of bystanders and researchers alike.

Diagnosis, vaccination and cure - The laboratory diagnosis of Chagas disease was no longer a problem in 1982. Serological diagnosis was ripe for the nationalscale epidemiological survey that preceded the launching of the Chagas control program in the 1980s (Camargo et al. 1984). However, serology could not distinguish between present and past infections. Ever since, efforts have been made to find serological (Krettli \& Brener 1976, Krettli 1980) or molecular markers of cure, but the problem persists. Without a diagnostic method with such capabilities, the actual effectiveness of a vaccine cannot be properly evaluated, not only in experimental models, but also in humans. As we said in 1982 and I reiterated at later opportunities (Camargo 1984, 2000), due to the silent and slow-evolving pathology of chronic Chagas, the evaluation of the effectiveness of a vaccine would take years. Thus, even if we had already overcome all laboratory and experimental barriers to developing a heroic vaccine capable of attenuating the acute phase, the field tests designed to assess whether such a vaccine could prevent chronic disease in man would take decades of clinical observation. It would take at least two or three decades, in the favourable (although unfortunate) scenario that there was a population to vaccinate, as discussed in item 3. The situation has not improved since 1982 and it is dismaying to see that the molecular advances in the development of candidate antigens and vaccines have not been accompanied by the development of experimental models for Chagas disease, nor by methods to ascertain its cure.

\section{Question 6 - What is new?}

New techniques, new scenarios, new problems - In 1982, we registered 49 full papers on vaccination attempts published in regular scientific journals and found more than 150 reports in Brazilian and Argentine meetings alone. In these attempts, the antigens used were: "avirulent" or attenuated strains of T. cruzi; culture forms of non-pathogenic insect trypanosomatids; killed culture and blood forms and sub-cellular fractions and purified, cellular or cell-surface antigens of T. cruzi or other trypanosomatids. Such attempts may not have stopped but, apparently, editors have stopped publishing them. Exceptionally, one or another attempt with living trypanosomatids has reached the scientific press in re- 
cent times (Basso et al. 2008). Despite many optimistic claims by authors, all vaccination attempts failed to confer sterile immunity. At best, they increased the survival rates or prevented the death of vaccinated animals after a $T$. cruzi virulent challenge. The animal model used was always the mouse, with three or four exceptions. Adjuvants were used sporadically. The vaccination and challenge routes were always sub-cutaneous or intraperitoneal in a few instances.

Things have changed in recent years. The DNA vaccine approach has taken over the scene. Initially, T. cruzi surface genes inserted in plasmids have been tested, but they also failed to induce sterile immunity in mice (Wizel et al. 1997, 1998, Costa et al. 1998, Boscardin et al. 1999). The choice of a plasmid stimulatory of Type I immunity as the vector for two surface genes induced total protection against a virulent challenge. The parasitaemia was null, but unfortunately the model used was the mouse, which provided information as a "first approximation" only (Machado et al. 2006). Proposed therapeutic vaccines represent a departure from the allor-none protection model. Since DNA vaccines are in principle capable of producing antigens for the duration of the life of the vaccinated mice, they represent a lifelong source of antigens that may induce protection or reduce the severity of the "disease" in mice, but only in mice (Garg \& Tarleton 2002, Zapata-Estrella et al. 2006, Sanchez-Burgos et al. 2007).

An alternative form of vaccination, mucosal or oral vaccination (Hoft et al. 1996, Schnapp et al. 2002, Hoft $\&$ Eickhoff 2005), although tested with certain success in mice only, finds incidental support in the current epidemiology of Chagas in the sense that it may prevent mucosal penetration and proliferation of $T$. cruzi.

Presently, new acute cases of Chagas disease in Brazil result from blood transfusion, trans-placental transmission and oral infection. The latter form results from the accidental ingestion of grinded triatomines carrying T. cruzi originating from wild animals. Triatomines have been accidentally grinded with fruit in the preparation of juices of açai (a palm tree widespread in Amazonia) and sugar cane. Clearly accidental, these outbreaks of oral infection can occur anywhere in the country, but have been more frequent in Amazonia. The episodes usually strike dozens of people at once, are serious and often fatal, but are always limited in space and time. There have not been more than 200 or 300 such outbreaks (Umezawa et al. 1996, Cardoso et. al. 2006, Coura 2006, Aguilar et al. 2007, Roque et al. 2008, Valente et al. 2008).

Would an oral vaccine be of help in preventing these Chagas outbreaks? No. Even if it prevented mucosal infection it would be of no use as a vaccine. This is because, again, we cannot define the population at risk.

Finally, since vector control was effective in curbing Chagas transmission in Brazil and since vaccines cannot be used at the moment to prevent the current forms of Chagas transmission (transfusive, trans-placental or accidental), does this mean that a vaccine against Chagas disease is unnecessary?
No, it does not. It may be unnecessary for Brazil at the moment, but Chagas is still endemic in large segments of Central and South America where close to 100 million people are still at risk. Vector control programs are under way, but they depend on reliable sanitary services, economic resources and political resolve. This is not a trivial conjunction of factors and even where they already coexist, political turmoil and economical crises may endanger any vector control program that relies on stability. In contrast, vaccinated people will remain immune through political unrest, economic fluctuations and the not-uncommon episodes of public health failure.

\section{REFERENCES}

Aguilar HM, Abad-Franch F, Dias JCP, Junqueira ACV, Coura JR 2007. Chagas disease in the Amazon Region. Mem Inst Oswaldo Cruz 102: 47-55.

Anez N, Carrasco H, Parada H, Crisante G, Rojas A, Fuenmayor C, Gonzalez N, Percoco G, Borges R, Guevara P, Ramirez J 1999. Myocardial parasite persistence in chronic Chagas patients. Am J Trop Med Hyg 70: 726-732.

Basso B, Moretti E, Fretes R 2008. Vaccination with epimastigotes of different strains of Trypanosoma rangeli protects mice against Trypanosoma cruzi infection. Mem Inst Oswaldo Cruz 103: 370-374.

Boscardin SB, Ramirez MI, Santori F, Yoshida N, Franco da Silveira J 1999. DNA vaccination with a gene that encodes the glycoprotein of $82 \mathrm{kDa}$ (gp82) of metacyclic trypomastigotes of Trypanosoma cruzi. Mem Inst Oswaldo Cruz 94: 182.

Brener Z, Andrade Z 1979. Trypanosoma cruzi e doença de Chagas, Gunabara Koogan, Rio de Janeiro, 463 p.

Brener Z, Camargo EP 1982. Perspectives of vaccination on Chagas' disease. Pontificiae Acad Scient Scripta Varia 47: 145-168.

Brisse S, Dujardin JC, Tibayrenc M 2000. Identification of six Trypanosoma cruzi lineages by sequence-characterised amplified region markers. Mol Biochem Parasitol 111: 95-105.

Camargo EP 1984. Immunoprotection in Chagas disease. Mem Inst Oswaldo Cruz 79: 169-172.

Camargo EP 2000. Vacinas e seu valor na prevenção da doença de Chagas. Rev Pat Tropical 29: 9-23.

Camargo EP, Barbieri CL, Jankevicius JV 1982. Possible artifacts in the radioiodination of surface proteins of trypanosomatids. J Immunol Methods 52: 245-253.

Camargo M, Silva G, Castilho E, Silveira A 1984. Inquérito serológico de prevalência da infecção chagásica no Brasil, 1975-1980. Rev Inst Med Trop Sao Paulo 26: 192-204.

Cardoso AVN, Lescano SAZ, Amato Neto V, Gakiya E, Santos SV 2006. Survival of Trypanosoma cruzi in sugar cane used to prepare juice. Rev Inst Med Trop Sao Paulo 48: 287-289.

Cortez M, Emperaire L, Piccinali R, Gürtler R, Torrico F, Jansen A, Noireau F 2007. Sylvatic Triatoma infestans (Reduviidae: Triatominae) in the Andean valleys of Bolivia. Acta Tropica 102: 47-54.

Costa F, Franchin G, Chioccola VLP, Ribeirão M, Schenkman S, Rodrigues MM 1998. Immunization with a plasmid DNA containing the gene of trans-sialidase reduces Trypanosoma cruzi infection in mice. Vaccine 16: 768-774.

Coura JR 2006. Transmission of chagasic infection by oral route in the natural history of Chagas disease. Rev Soc Bras Med Trop 39: 113.

Dias J 1987. Control of Chagas disease in Brazil. Parasitol Today 3: 336-341. 
Dias JCP, Schofield CJ 1999. The evolution of Chagas disease (American trypanosomiasis). Control after 90 years since Carlos Chagas discovery. Mem Inst Oswaldo Cruz 94: 103-121.

Dias JCP, Silveira AC, Schofield CJ 2002. The impact of Chagas disease control in Latin America: a review. Mem Inst Oswaldo Cruz 97: 603-612.

Fernandes O, Santos SS, Cupolillo E, Mendonca B, Derre R, Junqueira AC, Santos LC, Sturm NR, Naiff RD, Barret TV 2001. A mini-exon multiplex polymerase chain reaction to distinguish the major groups of Trypanosoma cruzi and T. rangeli in the Brazilian Amazon. Trans R Soc Trop Med Hyg 95: 97-99.

Galili U 1993. Evolution and pathophysiology of the human natural anti-galactosyl IgG (anti-Gal. antibody). Springer Semmin Immunology 15: 155-171.

Galili U, Andrews P 1995. Suppression of a-galactosyl epitopes synthesis and production of the natural anti-Gal antibody: a major evolutionary event in ancestral Old World primates. J Human Evol 29: 433-442.

Garg N, Tarleton R 2002. Genetic immunization elicits antige-specific protective immune responses and decreases disease severity in Trypanosoma cruzi infection. Infect Immun 70: 5547.

Guedes PMM, Veloso VM, Afonso LCC, Caliari MV, Carneiro CM, Diniz LF, Marques-da-Silva EA, Caldas IS, Do Valle Matta MA, Souza SM, Lana M, Chiari E, Galvão LM, Bahia MT 2009. Development of chronic cardiomyopathy in canine Chagas disease correlates with high IFN-?, TNF-a, and low IL-10 production during the acute infection phase. Vet Immunol Immunopathol 103: 43-52.

Guedes PMM, Veloso VM, Gollob KJ, Afonso LCC, Caldas IS, Vianna P, de Lana M, Chiari E, Bahia MT, Galvão LMC 2008. IgG isotype profile is correlated with cardiomegaly in Beagle dogs infected with distinct Trypanosoma cruzi strains. Vet Immunol Immunopathol 124: 163-168.

Hoft D, Eickhoff C 2005. Type 1 immunity provides both optimal mucosal and systemic protection against a mucosalli invasive intracellular pathogen. Infect Immun 73: 4934-4940.

Hoft D, Farrar P, Kratz-Owens K, Shaffer D 1996. Gastric invasion by Trypanosoma cruzi and induction of protective mucosal immune responses. Infect Immun 64: 3800-3810.

Hyland K, Engam D 2006. Further toughts on where we stand on the auttoimmunity hpotthesis of Chagas disease. Trends Parasitol 22: $101-102$.

Kierszenbaum F 2003. Views on the autoimmunity hypothesis for Chagas disease pathogenesis. FEMS immunol Medi Microbiol 37: 1-11.

Krettli AU 1980. Aspectos imunológicos da doença de Chagas. Ciênc Cult 31: 119-132.

Krettli AU, Brener Z 1976. Protective effects of specific antibodies in Trypanosoma cruzi infections. J Immunol 116: 755-760.

Leon JS, Engman DM 2001. Autoimmunity in Chagas heart disease. Int J Parasitol 31: 554-560.

Machado A, Cardoso J, Claser C, Rodrigues M, Gazzinelli R, BrunaRomero O 2006. Long-term protective immunity induced against Trypanosoma cruzi infection after vaccination with recombinant adenoviuses encoding amastigote surface protein-2 and transsialidase. Hum Gene Ther 17: 898-908.

Marcili A, Lima L Cavazzana M, Junqueira AC, Veludo HH, Maia da Silva F, Campaner M, Paiva F, Nunes VL, Teixeira MM 2009. A new genotype of Trypanosoma cruzi associated with bats evidenced by phylogenetic analysis using SSU rDNA, cytochrome $\mathrm{B}$ and Histone $\mathrm{H} 2$ genes and genotyping based on ITS 1 Rdna. Parasitology 136: 641-655.
Massad E 2008. The elimination of Chagas' disease in Brazil. Epidemiol Infect 136: 1153-1164.

Miles MA, Souza A, Povoa M, Shaw JJ, Lainson R, Toye PJ 1978. Isozymic heterogeneity of Trypanosoma cruzi in the first autochthonous patients with Chagas' disease in Amazonian Brazil. $\mathrm{Na}$ ture 272: 819-821.

Miles MA, Yeo M, Gaunt M 2003. Genetic diversity of Trypanosoma cruzi and the epidemiology of Chagas disease. In JM Kelly (ed), Molecular Pathogenesis of Chagas' Disease, Landes Bioscience, Austin, p. 1-15.

Moncayo A 2003. Chagas disease: current epidemiological trends after the interruption of vectorial and transfusional transmission in the Southern Cone countries. Mem Inst Oswaldo Cruz 98: 577-591.

Muniz J, Pena Azevedo A 1947. Novo conceito da patogenia de doença de Chagas - trypanosomiasis Americana - inflamação alérgica granulomatoide (a: e miocardite hiperergica (b: produzida em rhesus (macaca mullata) inoculados com formas mortas de cultivo de Schizotrypanum cruzi. Hospital (RJ) 32: 165-183.

Noireau F, Cortez MGR, Monteiro FA, Jansen AM, Torrico F 2005. Can wild Triatoma infestans foci in Bolivia jeopardize Chagas disease control efforts? Trends Parasitol 21: 7-10.

Roque ALR, Xavier SCC, da Rocha MG, Duarte ACM, D'Andrea PS, Jansen AM 2008. Trypanosoma cruzi. Transmission cycle among wild and domestic mammals in three areas of orally transmitted Chagas disease outbreaks. Am J Trop Med Hyg 79: 742.

Sanchez-Burgos G, Mezquita-Vega RG, Escobedo-Ortegon J, Ramirez-Sierra MJ, Arjona-Torres A, Ouaissi A, Rodrigues MM, Dumonteil E 2007. Comparative evaluation of therapeutic DNA vaccines against Trypanosoma cruzi in mice. FEMS Immunol Med Microbiol 50: 333-341.

Schnapp A, Eickhoff C, Sizemore D, Curtiss R, Hoft D 2002. Cruzipain induces both mucosal and systemic protection against Trypanosoma cruzi in mice. Infect Immun 70: 3065-3074.

Schofield CJ, Jannin J, Salvatella R 2006. The future of Chagas disease control. Trends Parasitol 22: 583-588.

Silveira AC, Vinhaes MC 1999. Elimination of vector-borne transmission of Chagas disease. Mem Inst Oswaldo Cruz 94: 405-411.

Souto RP, Fernandes O, Macedo AM, Campbell DA, Zingales B 1996. DNA markers define two major phylogenetic lineages of Trypanosoma cruzi. Mol Biochem Parasitol 83: 141-152.

Tarleton R L 2001. Parasite persistence in the aetiology of Chagas disease. Int J Parasitol 31: 550-554.

Tarleton R L 2003. Chagas disease: a role for autoimmunity? Trends Parasitol 19: 447-451.

Tarleton RL, Zhang L 1999. Chagas disease etiology: autoimmunity or parasite persistence? Parasitol Today 15: 94-99.

Umezawa ES, Shikanai-Yasuda MA, Gruber A, Pereira-Chioccola VL, Zingales B 1996. Trypanosoma cruzi defined antigens in the serological evaluation of an outbreak of acute Chagas disease in Brazil (Catolé do Rocha, Paraíba). Mem Inst Oswaldo Cruz 91: 87-93.

Umezawa U, Souza A, Cancino V, Marcondes Marcili, A Camargo, L, Camacho A, Stolf A, Teixeira M 2009. TESA-blot for the diagnosis of Chagas disease in dogs from co-endemic regions for Trypanosoma cruzi, Trypanosoma evansi and Leishmania chagasi. Acta Tropica, in press.

Vago A, Macedo A, Adad S, Rei D, Correa-Olveira R 1996. PCR detection of Trypanosoma cruzi DNA in oesophageal tissues of patients with chronic digestive Chagas disease. Lancet 348: 891-892. 
Valadares HMS, Pimenta JR, de Freitas JM, Duffy T, Bartholomeu DC, de Paula Oliveira R, Chiari E, Moreira MCV, Filho GB, Schijman AG 2008. Genetic profiling of Trypanosoma cruzi directly in infected tissues using nested PCR of polymorphic microsatellites. Int J Parasitol 38: 839-850.

Valente SAS, da Costa Valente V, das Neves Pinto AY, de Jesus Barbosa César M, dos Santos MP, Miranda COS, Cuervo P, Fernandes O 2008. Analysis of an acute Chagas disease outbreak in the Brazilian Amazon: human cases, triatomines, reservoir mammals and parasites. Trans Royal Soc Trop Med Hyg 103: 291-297.

Wizel B, Garg N, Tarleton RL 1998. Vaccination with trypomastigote surface antigen 1-encoding plasmid DNA confers protection against lethal Trypanosoma cruzi infection. Infect Immun 66: 5073-5081.

Wizel B, Nunes M, Tarleton RL 1997. Identification of Trypanosoma cruzi trans-sialidase family members as targets of protective $\mathrm{CD}^{+} \mathrm{TC1}$ responses. J Immunol 159: 6120-6130.

Zapata-Estrella H, Hummel-Newell C, Sanchez-Burgos G, EscobedoOrtegon J, Ramirez-Sierra MJ, Arjona-Torres A, Dumonteil E 2006. Control of Trypanosoma cruzi infection and changes in Tcell populations induced by a therapeutic DNA vaccine in mice. Immunol Lett 103: 186-191.

Zhang L, Tarleton RL 1999. Parasite persistence correlates with disease severity and localization in chronic Chagas' disease. J Infect Dis 180: 480-486. 